Article

\title{
A Novel Genotype and First Record of Trypanosoma lainsoni in Argentina
}

\author{
Anahí G. Díaz ${ }^{1}$, Paula G. Ragone ${ }^{1}$, Fanny Rusman ${ }^{1}$, Noelia Floridia-Yapur ${ }^{1}$, \\ Rubén M. Barquez ${ }^{2}{ }^{\circledR}$, M. Mónica Díaz ${ }^{2}$, Nicolás Tomasini ${ }^{1, *}$ and Patricio Diosque ${ }^{1, *}$ \\ 1 Unidad de Epidemiología Molecular (UEM), Instituto de Patología Experimental, Universidad Nacional de \\ Salta-CONICET, 4400 Salta, Salta, Argentina; anahi1990gd@gmail.com (A.G.D.); \\ p_ragone@yahoo.com.ar (P.G.R.); fannyrusman@gmail.com (F.R.); narfy89@gmail.com (N.F.-Y.) \\ 2 Programa de Investigación de Biodiversidad Argentina (PIDBA), Facultad de Ciencias Naturales e \\ Instituto Miguel Lillo, Universidad Nacional de Tucumán-CONICET, 4000 San Miguel de Tucumán, \\ Tucumán, Argentina; rubenbarquez@csnat.unt.edu.ar (R.M.B.); mmdiaz@lillo.org.ar (M.M.D.) \\ * Correspondence: nicolas.tomasini@conicet.gov.ar (N.T.); patricio.diosque@unsa.edu.ar (P.D.)
}

Received: 31 July 2020; Accepted: 30 August 2020; Published: 4 September 2020

check for updates

\begin{abstract}
Trypanosomes are a group of parasitic flagellates with medical and veterinary importance. Despite many species having been described in this genus, little is known about many of them. Here, we report a genetic and morphological characterization of trypanosomatids isolated from wild mammals from the Argentine Chaco region. Parasites were morphologically and ultrastructurally characterized by light microscopy and transmission electron microscopy. Additionally, 18s rRNA and gGAPDH genes were sequenced and analyzed using maximum likelihood and Bayesian inference. Morphological characterization showed clear characteristics associated with the Trypanosoma genus. The genetic characterization demonstrates that the studied isolates have identical sequences and a pairwise identity of $99 \%$ with Trypanosoma lainsoni, which belongs to the clade of lizards and snakes/rodents and marsupials. To date, this species had only been found in the Amazon region. Our finding represents the second report of T. lainsoni and the first record for the Chaco region. Furthermore, we ultrastructurally described for the first time the species. Finally, the host range of T. lainsoni was expanded (Leopardus geoffroyi, Carenivora, Felidae; and Calomys sp., Rodentia, Cricetidae), showing a wide host range for this species.
\end{abstract}

Keywords: Trypanosoma lainsoni; Leopardus geoffroyi; Calomys spp.; $18 \mathrm{~S}$ rDNA genes; gGAPDH genes; morphology; transmission electron microscopy

\section{Introduction}

Trypanosomatids are unicellular parasites characterized by a single flagellum. This family belongs to the class Kinetoplastea, named for the presence of a large mitochondrion with numerous copies of circular DNA, organized in a compact structure called kinetoplast [1]. This class is composed of 12 parasitic genera with numerous species that can each parasitize either vertebrates, invertebrates, or even some plants [2-4]. Among them, Trypanosoma is a monophyletic group that infects all classes of vertebrate hosts [5-7], shows different morphological types during their dixenous life cycles, and are transmitted by blood-sucking invertebrates $[8,9]$.

Different phylogenetic groups within this genus have been delimitated by phylogenetic analyzes of the 18S rDNA and glycosomal glyceraldehyde phosphate dehydrogenase (gGAPDH) genes [5]. The most studied species within the genus Trypanosoma are those of medical and veterinary importance, such as Trypanosoma cruzi, T. brucei, T. vivax, and T. evansi. Conversely, very little is known about the other species of the genus Trypanosoma. An example is the phylogenetic group of trypanosomes of 
lizards and snakes (e.g., T. serpentis, T. cascavelli, T. varani) [7]. After first descriptions and based on phylogenetic analyses, this group was expanded to also include parasites from rodents and marsupials, i.e., T. freitasi and T. lainsoni. Consequently, the clade was renamed to lizard and snake/rodent and marsupial (LSRM) [7,10-13]. Particularly, T. lainsoni was represented by a single isolate from a caviomorph rodent of the genus Mesomys in the northern state of Amazona, Brazil.

South America has a great number of trypanosome species, parasitizing a wide diversity of hosts. However, most of the reports on isolations are registered in Brazil [7,10-15], while in Argentina, just three species were reported: T. cruzi (the agent of Chagas disease), T. evansi, and T. vivax [16-19].

In this study, we analyze the phylogenetic relationships of trypanosomatids isolated from wild mammals from the Copo National Park, in the Argentine Chaco region. Particularly, we described a new genotype of T. lainsoni obtained from a Leopardus geoffroyi (Carnivora, Felidae) and from two rodents by analyzing the rDNA and gGAPDH genes. In addition, we provide the first cell ultrastructure description for this species.

\section{Results}

\subsection{Light and Transmission Electron Microscopy Classified the Three Isolates to the Genus} Trypanosoma (Trypanosomatidae)

Light microscopic observations of in vitro cultures showed that the three isolates were morphologically compatible with trypanosomatids. These isolates presented cells with an average length of $33.4 \mu \mathrm{m}$ and tapered shapes, with a single flagellum, a nucleus, and a kinetoplast (Figure 1A). The forms identified in culture were: trypomastigotes (central nucleus with a kinetoplast and posterior flagellum) (Figure 1B), epimastigotes (central nucleus with the kinetoplast and the flagellum anterior to nucleus) (Figure 1C), and spheromastigotes (nucleus, central kinetoplast, and the flagellum surrounding the body) (Figure 1D).

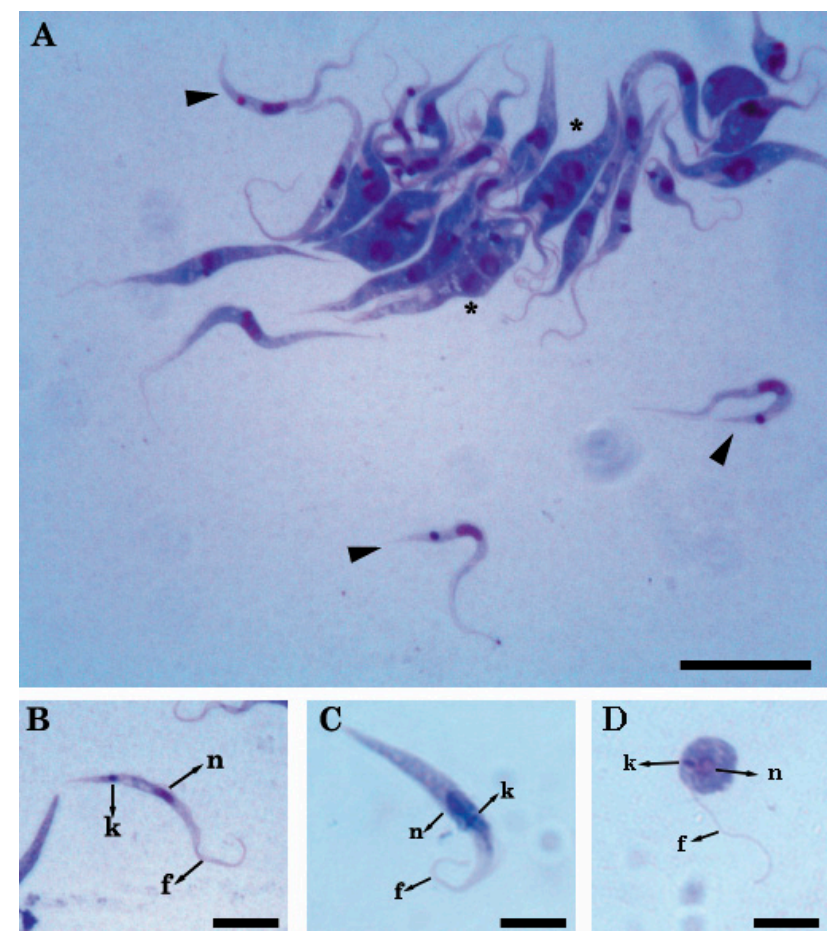

Figure 1. Microphotography at $1000 \times$ of parasites in cultures with May Grünwald and Giemsa. (A) Exponential phase culture: trypomastigotes (arrow) were observed among the epimastigotes; the dividing epimastigotes are denoted with an asterisk; (B) Trypomastigote; (C) Epimastigote; (D) Spheromastigote. Nucleus $=\mathrm{n}$, kinetoplast $=\mathrm{k}$, flagellum $=\mathrm{f}$. Scale bars: (A) $20 \mu \mathrm{m}$ and (B-D) $10 \mu \mathrm{m}$. 
In the culture conditions, a great variation was observed in the length of epimastigotes throughout the exponential phase, from 25.6 to $72.5 \mu \mathrm{m}$ (Figure 2A). In addition, we observed replicating epimastigotes, identified by the presence of two nuclei, two flagella, and a single kinetoplast (Figure 2B). On the other hand, the trypomastigotes were observed at the end of the exponential stage and were smaller than epimastigotes (Table 1; Figure 2C). Finally, transitional forms between epimastigotes and trypomastigotes were also detected (Figure 2D). The size of these last parasites was variable (Table 1).
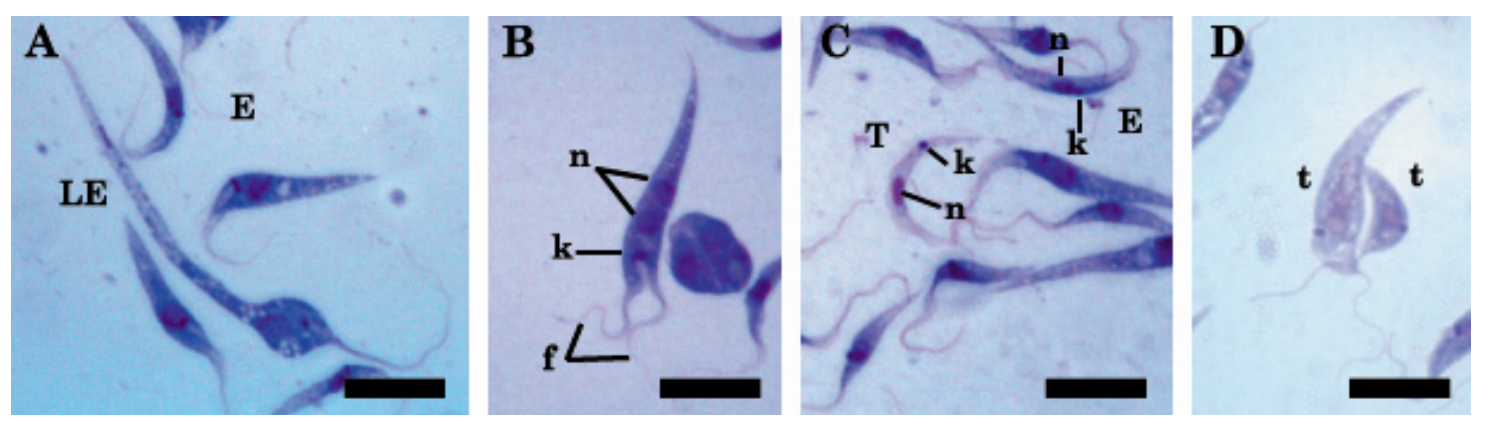

Figure 2. Microphotography at $1000 \times$ of parasites in cultures with May Grünwald and Giemsa. (A) The difference in sizes between a long epimastigote (LE) and a simple epimastigote (E) is observed; (B) Dividing epimastigote with two nuclei, two flagella, and one kinetoplast; (C) Trypomastigote (T) smaller than epimastigote (E); (D) Transitional form ( $\mathrm{t}$ ). Nucleus = n, kinetoplast = k, flagellum $=\mathrm{f}$. Scale bar (A-D) $10 \mu \mathrm{m}$.

Table 1. Measurements of the different forms observed by light microscopy. Mean \pm Standard Deviation.

\begin{tabular}{ccccc}
\hline Form & $\begin{array}{c}\text { Body Average } \\
\text { Length }\end{array}$ & $\begin{array}{c}\text { Free Average } \\
\text { Flagellum }\end{array}$ & $\begin{array}{c}\text { Total Average } \\
\text { Length }\end{array}$ & Average Width \\
\hline Trypomastigote & $18.15 \pm 6.26$ & $8.67 \pm 3.02$ & $28.13 \pm 6.74$ & $1.5 \pm 0.47$ \\
\hline Epimastigote & $21.88 \pm 3.28$ & $11.43 \pm 3.81$ & $33.61 \pm 6.08$ & $2.3 \pm 0.8$ \\
\hline Long Epimastigote & $44.25 \pm 7.22$ & $17.13 \pm 6.32$ & $61.85 \pm 13.51$ & $3.84 \pm 1.55$ \\
\hline Transitional form & $13.98 \pm 6.76$ & $12.85 \pm 3.52$ & $27.26 \pm 9.69$ & $4.19 \pm 1.34$ \\
\hline Spheromastigote & $6.12 \pm 1.7$ & $16.27 \pm 5.19$ & $23.01 \pm 5.64$ & $4.29 \pm 1.8$ \\
\hline
\end{tabular}

In concordance with light microscopy images, the samples analyzed by TEM (Transmission Electron Microscopy) revealed typical structures of Trypanosoma, such as a kinetoplast, flagellar structures (flagellar pocket, basal bodies), many vesicular bodies, acidocalcisomes, reservosomes, lipid bodies, and a cytostome. Most of the observed forms were epimastigotes (Figure 3A,B). In these forms, a large nucleus can be recognized in a central position with an average length of $1.29 \pm 0.17 \mu \mathrm{m}$ and an average width of $1.03 \pm 0.13 \mu \mathrm{m}$ (Figure 3C). In addition, a rod-shaped kinetoplast was observed without a clear differentiation of ridges (Figure 3D) and an average length of $0.94 \pm 0.32 \mu \mathrm{m}$. The kinetoplast was anterior and next to the nucleus and a single asymmetrical flagellar pocket. This structure had a probasal body on the bulky side and a basal body on the other one (Figure 3E). Furthermore, the cytostome (Figure 3F) was located near the flagellum and the kinetoplast. A great number of vesicles of variable size and dark coloration, acidocalcisomes, and rounded lipid bodies were also observed (Figure 3G). Finally, reservosomes (rounded structures) were visualized along some epimastigotes (Figure 4A,C). 

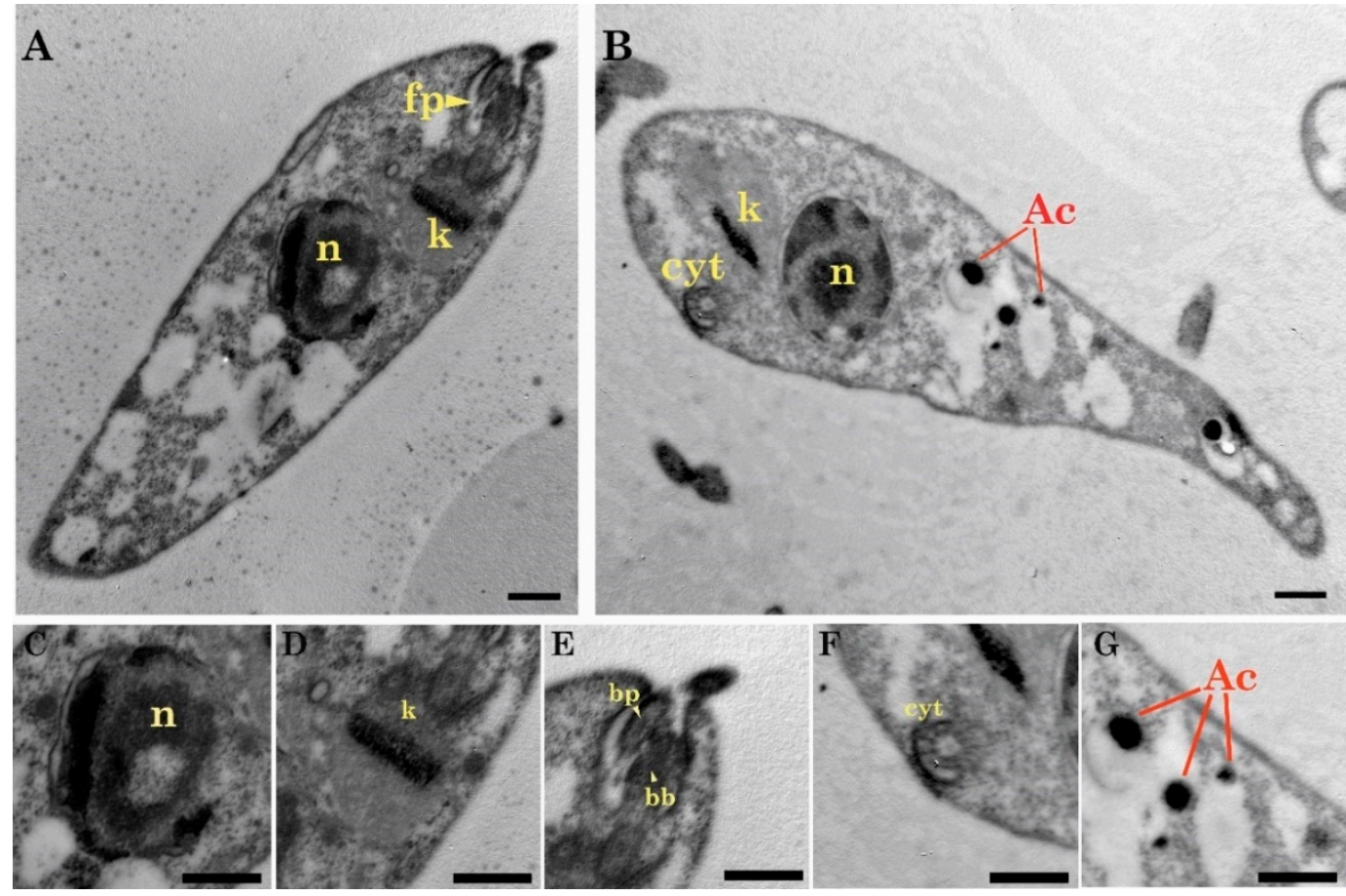

Figure 3. Electron micrograph of the exponential growth phase. (A) Epimastigote with a tapered shape, central nucleus (n), anterior kinetoplast (k) in a position close to the flagellar pocket (fp); (B) epimastigote showing the position of the nucleus (n), kinetoplast (k), cytostome (cyt) and acidocalcisomes (Ac); (C) Nucleus (n) with chromatin spots on the inner side of the nuclear membrane; (D) Rod shaped kinetoplast (k); (E) Structure of the flagellum: basal body (bb), probasal body (pb), and cross section of the flagellum; (F) Cross section cytostome (cyt); (G) Acidocalcisomes (ac). Scale bar (A-B) $1 \mu \mathrm{m}$; (C-G) $0.5 \mu \mathrm{m}$ ).
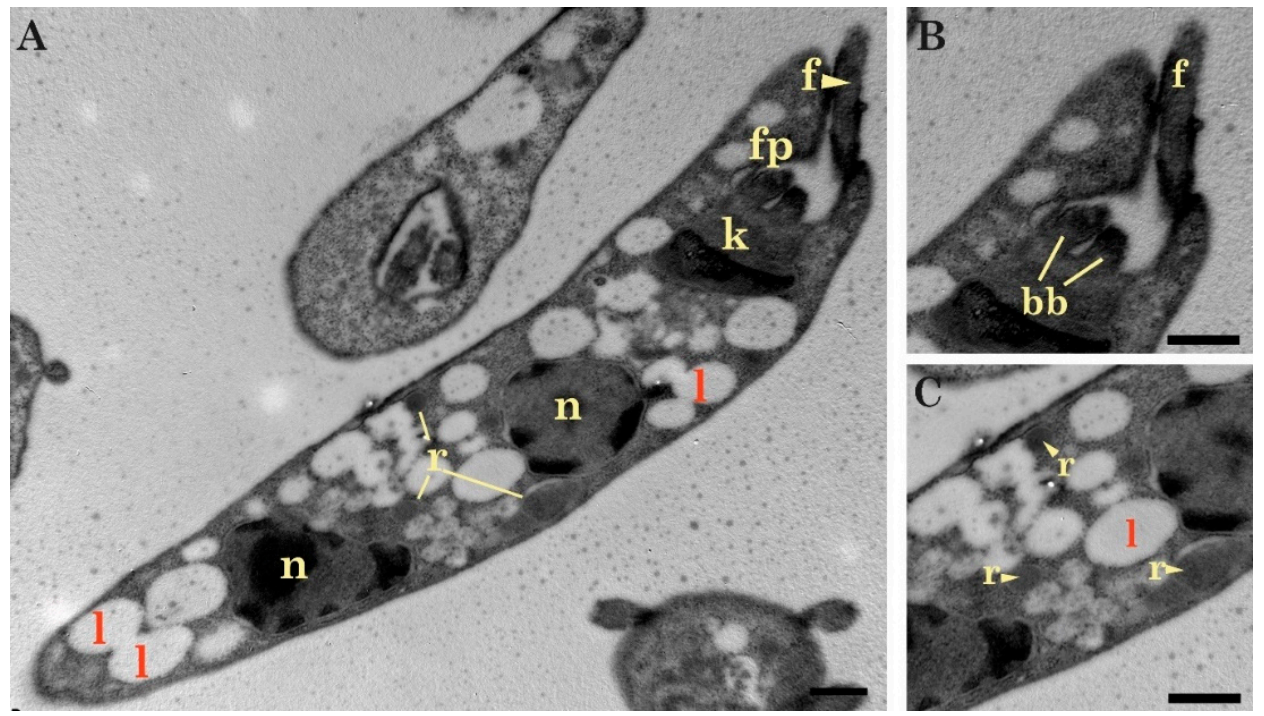

Figure 4. Transmission electron micrograph of the isolated parasites in the exponential phase. (A) Division cell with two nuclei (n), a kinetoplast (k), and a single flagellar pocket (fp); (B) Flagellar pocket with two basal body (bb); (C) Numerous vesicular bodies highlighting lipid bodies (l) and reservosomes (r). Scale bar $(\mathbf{A}-\mathbf{C}) 0.5 \mu \mathrm{m}$. 
2.2. The Isolated Trypanosomes Belong to Trypanosoma lainsoni and Constitutes a Novel Genotype Different to the Brazilian Isolate

The alignment of the first sequences obtained for the $18 \mathrm{~S}$ rDNA gene $(610 \mathrm{bp})$ revealed that the three isolates Ca37, Ca47, and Le29 are completely identical. This was subsequently corroborated with the sequence of the gGAPDH gene (528 bp). These sequences were analyzed by BLAST and they were similar to T. lainsoni, although not identical (Table S1).

The complete 18S rDNA gene sequence was obtained from Le29 (2659 bp) and used in the following analyses. Like the first sequenced fragment, the Le29 isolate was found to have $99 \%$ shared identity with the T. lainsoni species for the $18 \mathrm{~S}$ rDNA complete gene (Table S1). Furthermore, the gGAPDH and 18S rDNA genes of the Le29 isolate had pairwise identity greater than $90 \%$ with the sequences published for the T. freistasi, T. gennarii, and T. casacavelli species $[7,10]$.

The high pairwise sequence identity between Le29 and the only T. lainsoni isolate reported in Brazil indicated that they belong to the same species. However, we made a phylogenetic analysis in order to address such genetic distance in the context of other distances in the LSRM phylogenetic group. The maximum likelihood and Bayesian methods generated phylogenetic trees with topologies similar to those reported for the genus Trypanosoma (Figure 5, Figures S1 and S2). The trees for the gGAPDH gene and for the concatenated alignment showed very short genetic distances $(0.6 \%)$ between the sequences of the Le29 isolate and the Brazilian T. lainsoni (Figure 5 and Figure S1), which prevent us separating them into different species (Table S2).

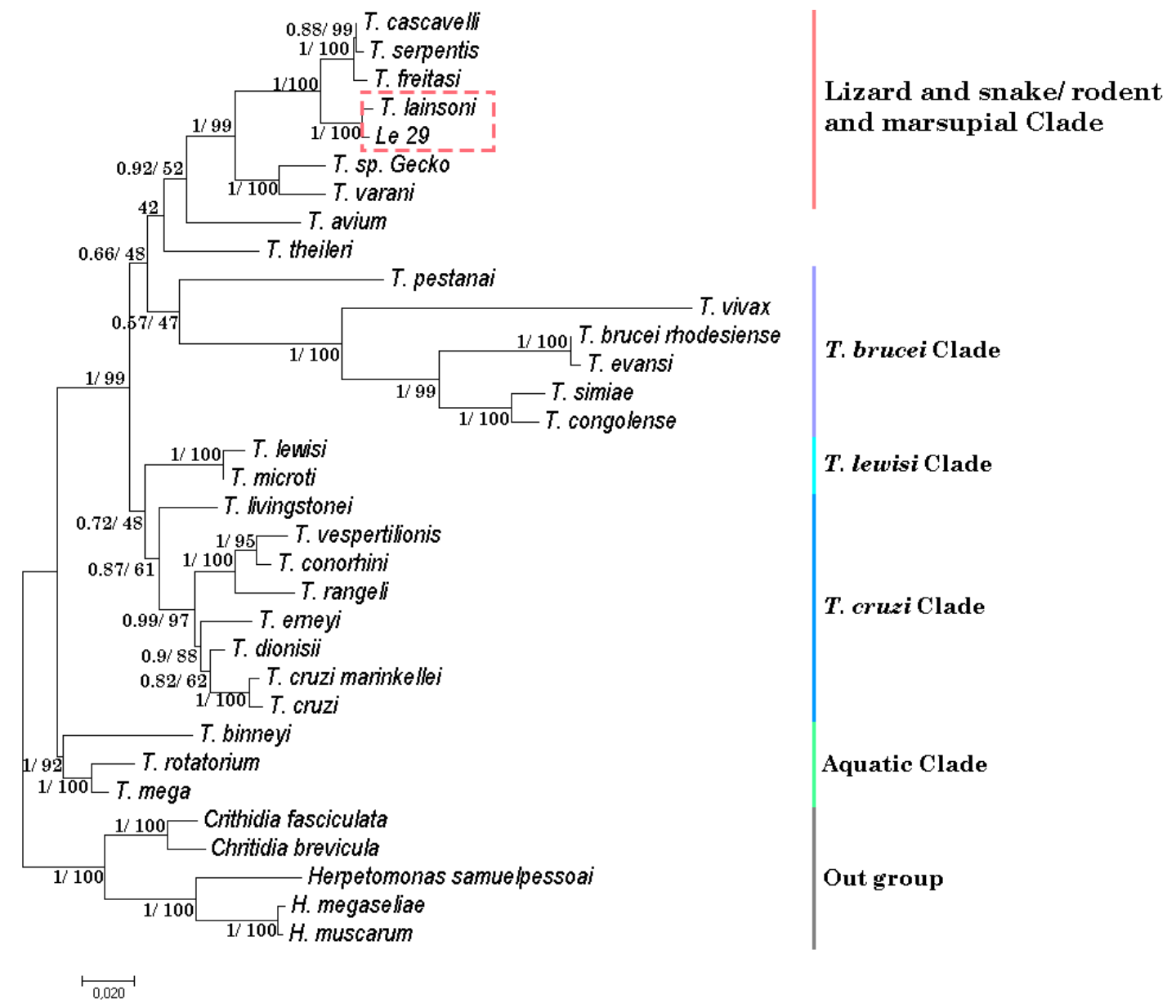

Figure 5. Phylogenetic analysis performed by the maximum likelihood method of the concatenated $18 \mathrm{~S}$ rDNA and gGAPDH genes in 33 species of trypanosomatids. Species of the genera Herpetomonas and Crithidia were included as out groups. The two values at nodes represent: Bayesian analysis support/ML method bootstrap value. Trypanosoma lainsoni and Le29 are found within the LSRM clade. 


\section{Discussion}

In this study, the morphological and genetic characterization of three trypanosomatid isolates was performed. The parasites were isolated from mammalian hosts in the Copo National Park, Santiago del Estero province, in the Argentine Chaco region. They were identified as Trypanosoma lainsoni, a species previously described from the blood of a rodent (genus Mesomys) in Brazil [13] and later included within the LSRM clade [10]. This report represents the first isolate of this species recorded for Argentina. Furthermore, this paper constitutes the second report of T. lainsoni and the first cell ultrastructure description for the species. Additionally, we found T. lainsoni in the Order Carnivora (Leopardus geoffroyi), showing a wider host range for the species.

The morphology observed under light and electron microscopy showed structures according to the Kinetoplastea class and the Trypanosomatidae family. In addition, the presence of stages such as epimastigotes and trypomastigotes, as well as a great variety of intermediate forms, were compatible with those described for the genus Trypanosoma. In the same way, typical internal cell structures of Trypanosoma, as structures related to the feeding of cells such as the cytostome and the reservosomes. These organelles are characteristic of trypanosomes, where the macromolecules used during the metacyclic process from epimastigote to trypomastigote are stored [20]. On the other hand, the kinetoplast in the epimastigote stage presented a rod-shape, similar to kinetoplasts of trypanosomes in the same phylogenetic group (LSRM clade) $[7,21]$ and a similar thickness compared to other trypanosomes [7].

The morphometric data revealed that $T$. lainsoni isolates described here have similar sizes than those from the Amazon region in Brazil ( $36.2 \mu \mathrm{m}$ and $33.4 \mu \mathrm{m}$, respectively). Based on this size, the Amazonian isolate was considered as part of the subgenus Megatrypanum [10,12,22]. Consequently, T. lainsoni was granted the status of a new species because there was no record of Megatrypanum isolates from a rodent caviomorph [13]. Afterwards, other studies reaffirmed the status of new species according to molecular data [10]. In addition, the presence of T. lainsoni in mammalian hosts is reinforced. However, it is important to note that the criterion to define species based on the host is weak because it is known that many trypanosomes do not usually have host specificity. Consequently, phylogenetic techniques are more useful to define species [11], at least in trypanosomatids, and prevent us from defining a new species based only on the host where the parasite was isolated. The genetic characterization determined that the three isolates from the Chaco region share $100 \%$ similarity in the partial sequence of the $18 \mathrm{~S}$ rDNA gene and the complete sequence of the gGAPDH gene, indicating that they are the same species and the same genotype, although we cannot discard that they may differ in other regions of the $18 \mathrm{~s}$ rDNA or in other genomic regions. However, the isolates that we describe here are a different genotype from those previously described from the Amazon region, based on the sequences studied. The latter is not surprising considering the geographical distances and the different hosts from which the isolates from Brazil and Argentina were obtained.

The phylogenetic tree built with the concatenated $18 \mathrm{~S}$ rDNA and gGAPDH genes raised questions about the taxonomic criteria currently used to classify parasites isolated from different hosts as different species. The concatenated tree showed a low phylogenetic distance between some species. Such distances were less than the distance found between strains belonging to a same species, such is the case of T. cruzi strains, which ranges from $0 \%$ to $1 \%$ (Table S3). An example is observed among the isolates of the species T. serpentis and T. cascavelli, which have a phylogenetic distance of $0.2 \%$, less than that found between the Le29 isolate and the T. lainsoni isolate from Brazil (0.6\%) (Table S2). In this sense, we consider that at least in some cases, the criteria used to define new species within the genus Trypanosoma are unclear. Further analysis and consensus would be required in order to clearly define how much genetic distance should be considered sufficient to differentiate species in this group. Consequently, because host and distribution range appear not to be useful for defining Trypanosoma species in many cases and the genetic distance between Le29 and T. lainsoni did not exceed $1 \%$ (the distance between some T. cruzi strains), we consider that Le29 should be considered as a different genotype of $T$. lainsoni. No vector was identified in the park despite capture efforts with light 
traps. Suspicious vectors could be those already reported for the LSRM clade, such as flies, sand flies, and various species of ticks [21,23-27]. On the other hand, the oral route cannot be ruled out since it is probably the most frequent mechanism of transmission of trypanosomes in the wild cycle [28]. Taking into account that the diet of L. geoffroyi is mainly composed of rodents of the Akodon and Calomys genera [29], we think that oral transmission would be a possible route of circulation of T. lainsoni in the studied geographic area.

Finally, it would be interesting to elucidate if T. lainsoni naturally infects domestic animals or even humans. In the same way, taking into account that T. cruzi (the causal agent of Chagas disease) is highly endemic in the Chaco region where T. lainsoni was isolated, it would be useful to know whether T. lainsoni infection can interfere with the serological diagnosis of T. cruzi infection. The latter could be addressed through studies of experimental infections in mice.

\section{Materials and Methods}

\subsection{Wild Animal Capture}

The parasites were isolated from Leopardus geoffroyi (Carnivora, Felidae) and two Calomys sp. (Rodentia, Cricetidae). These hosts were captured in Copo National Park, Santiago del Estero, Argentina, within the Chaco region $\left(25^{\circ} 58^{\prime} \mathrm{S}, 61^{\circ} 53^{\prime} \mathrm{W}\right)$. Small mammals were trapped using Sherman traps, while medium size mammals were captured using Tomahawk traps. All animals were anesthetized with isofluorane and blood samples were obtained by cardiac puncture in small mammals and by venipuncture in medium size mammals. The animals were manipulated in concordance with the recommendations of the Institutional Committee for the Care and Use of Experimental Animals of Argentina. Ethical approval number 31/2014, date 10/21/2014, National Parks Administration, Argentina.

\subsection{Isolation and Culture of Trypanosomes}

Trypanosomatids were isolated from blood samples. Samples of $500 \mu \mathrm{L}$ were placed in biphasic medium composed of a solid phase ( $4 \%$ agar supplemented with rabbit blood) and a liquid phase composed of Liver Infusion-Triptose medium (LIT) supplemented with $20 \%$ fetal bovine serum, hemin $20 \mu \mathrm{g} / \mathrm{mL}$, penicillin $100 \mathrm{IU}$, and streptomycin $100 \mu \mathrm{g} / \mathrm{mL}$ under shaking at $25^{\circ} \mathrm{C}$. After corroborating the presence of trypanosomatids, the isolates were maintained in the laboratory in the same medium. One isolate was obtained from Leopardus geoffroyi (named Le29) and two from Calomys sp. (named Ca37 and Ca47).

\subsection{Morphological Characterization}

\section{Light and Electron Microscopy}

Daily culture samples of each isolate were observed under light microscopy at 1000x to identify and measure different parasite forms. Additionally, a smear on a glass slide per sample was fixed with fetal bovine serum and subsequently stained using the May Grünwald and Giemsa staining method and observed at $1000 \times$. Different parasite forms were compared with those described for cultivated parasites of the Trypanosoma cruzi species [30].

For transmission electron microscopy, a sample from the exponential growth phase of the Le29 isolate was taken and fixed with $2 \%$ glutaraldehyde and analyzed by the Service of the Electron Microscopy Center of the Faculty of Veterinary Sciences of the National University of La Plata, Argentina. The obtained images were processed and compared with those available in literature. 


\subsection{Molecular Characterization}

\subsubsection{PCR and Sequencing of $18 \mathrm{~S}$ rDNA and gGAPDH}

Total DNA was extracted from each isolate with the commercial DNA Puriprep T-kit (INBIO HIGHWAY; Buenos Aires, Argentina). The 18S rDNA and gGAPDH genes [31,32] were amplified by PCR. The amplification of the $18 \mathrm{~S}$ rDNA gene was carried out in two steps. First, a $610 \mathrm{bp}$ fragment was amplified using the 18sLeft and 18sRight primers (Table S4). Secondly, the entire gene of approximately $2000 \mathrm{bp}$ was amplified using the $18 \mathrm{sp} 3 \mathrm{pL}$ and $18 \mathrm{sp} 3 \mathrm{pR}$ primers (Table S4). Cycling conditions were: $95^{\circ} \mathrm{C}$ for $2 \mathrm{~min}$, followed by 35 cycles at $94^{\circ} \mathrm{C}$ for $30 \mathrm{~s}, 57^{\circ} \mathrm{C}$ for $30 \mathrm{~s}, 72^{\circ} \mathrm{C}$ for $2 \mathrm{~min}$, and $72{ }^{\circ} \mathrm{C}$ for $20 \mathrm{~min}$. On the other hand, amplification of $528 \mathrm{bp}$ of the gGAPDH gene was performed using the ggapdh $2 \mathrm{~F}$ (5'-TGCACGGAARRTTTAAGCAC-3') and ggapdh2R (5'-GAGCTTCGGTTGTCGTTGAT-3') primers. Cycling conditions were: $95^{\circ} \mathrm{C}$ for $2 \mathrm{~min}$, followed by 35 cycles at $94{ }^{\circ} \mathrm{C}$ for $20 \mathrm{~s}, 57^{\circ} \mathrm{C}$ for $30 \mathrm{~s}, 72{ }^{\circ} \mathrm{C}$ for $1 \mathrm{~min}$, and $72{ }^{\circ} \mathrm{C}$ for $10 \mathrm{~min}$.

Each amplicon was purified and sequenced by means of an automatic ABI3130 capillary sequencer (Applied Biosystems; Waltham, MA, USA), provided by the Sequence Service Cerela-CONICET (Tucumán). Internal primers were used to optimize the sequencing of 18S (Table S4).

\subsubsection{Data Analysis}

The obtained electropherograms were manually edited using Chromas v2.6.5 (https://technelysium. com.au/wp/; Technelysium Pty Ltd., South Brisbane, Australia). The edited sequences were uploaded to the GenBank (codes in Table 2) to be compared with other available trypanosome sequences (Table S5) by using the version 7.0.26 of MEGA (MEGA Software, PA, USA) [33]. For the alignment of the 18S rDNA gene, the Gblocks tool (http://phylogeny.fr) was used to eliminate the hypervariable regions.

Table 2. This table shows the location codes of the sequences in GenBank.

\begin{tabular}{cc}
\hline \multicolumn{2}{c}{ Partial Sequence } \\
\hline Le29 & MT363779 \\
\hline Ca37 & MT363780 \\
\hline Ca47 & MT363781 \\
\hline \multicolumn{2}{c}{ Complete Sequence } \\
\hline Le29 & MT373343/MT373412 \\
\hline Ca37 & MT363778/MT373413 \\
\hline Ca47 & MT363777/MT373414 \\
\hline
\end{tabular}

The following alignments were considered for phylogenetic analysis: (i) the sequences of the $18 \mathrm{~S}$ rDNA gene, (ii) the sequences of the gGAPDH gene, and (iii) the concatenated sequences of the $18 \mathrm{~S}$ rDNA and gGAPDH genes. MLSTest software (v1.0.1.23) [34] was used to concatenate alignments.

Phylogenetic analysis for both genes was performed by the maximum likelihood (ML) method, using MEGA, and the Bayesian method, using MrBayes v.3.2.7a [35], in the CIPRES platform [36]. The trees made by ML were constructed with 1000 Bootstrap repetitions. The best substitution model was selected using the AIC criterion in MEGA. The tree for the $18 \mathrm{~S}$ rDNA gene was performed using the Kimura two parameters substitution model [37]. The Tamura-three parameters substitution model was used [38] for phylogenetic inference in the gGAPDH gene. Finally, the time-reversible general substitution model was used for maximum likelihood inference on concatenated alignments. All models were used with a discrete Gamma $(+G)$ distribution of the substitution rate between sites and assuming the existence of a fraction of invariable sites (+I). The HKY85 model [39] with an invariant site ratio and gamma distribution was used for the concatenated alignments and for the 
individual genes, which were run for 1,000,000 generations, with trees sampled every 100 generations, and $25 \%$ of the early sample trees were discarded as burn-in.

In this study, and considering most studied trypanosomes, we used a phylogenetic criterium to define species boundaries. At least $1 \%$ of genetic distance to any other species was considered as the cutoff to propose a novel species. Model p-corrected distances between isolates were calculated using the MEGA program.

Supplementary Materials: The following are available online at http://www.mdpi.com/2076-0817/9/9/731/s1, Table S1: Analysis of the sequences of the $18 \mathrm{~S}$ rDNA genes (2659 bp) and gGAPDH (528 bp) obtained from the Le29 isolate in BLAST (Basic Local Alignment Search Tool); Table S2: Values of genetic distance of the species of the genus Trypanosoma of concatenated alignment between the 18S rDNA and gGAPDH genes in percentage \%; Table S3: Values of genetic distance of the T. cruzi strains; Table S4: This table shows the external and internal primers used in the sequencing of the $18 \mathrm{~S}$ rDNA gene; Table S5: Hosts and geographic origin of trypanosomatids and GenBank accession numbers of sequences included in this study; Figure S1: Phylogenetic reconstruction performed by the maximum likelihood method from $528 \mathrm{bp}$ of the gGAPDH gene in 35 species of trypanosomatids; Figure S2: Phylogenetic reconstruction performed by the maximum likelihood method from $1431 \mathrm{bp}$ of the $18 \mathrm{~S}$ rDNA gene in 34 species of trypanosomatids.

Author Contributions: Conceptualization, P.D.; fieldwork, P.D., N.T., R.M.B., and M.M.D.; laboratory investigation, A.G.D., P.G.R., F.R., N.F.-Y., and N.T.; data analysis, A.G.D., P.G.R., and N.T.; writing—original draft preparation, A.G.D.; writing - review and editing, P.G.R., N.T., and P.D.; funding acquisition, P.D. All authors have read and agreed to the published version of the manuscript.

Funding: This research was funded by a grant from ANPCyT, Argentina (PICT-2012-2174).

Acknowledgments: We would like to thank Alejandro Uncos, Federico Ramos, Renato Uncos, María Celia Mora, and Gabriela Rojas (Instituto de Patología Experimental, Facultad de Ciencias de la Salud, Universidad Nacional de Salta, Argentina) for their technical assistance in this project.

Conflicts of Interest: The authors declare no conflict of interest. The funders had no role in the design of the study; in the collection, analyses, or interpretation of the data; in the writing of the manuscript, or in the decision to publish the results.

\section{References}

1. Vickman, K. The Diversity of the kinetoplastid flagellates. In Biology of the Kinetoplastida; Lumsden, W.H.R., Evans, D.A., Eds.; Academic Press: London, UK; New York, NY, USA; San Francisco, CA, USA, 1976; pp. 1-34.

2. Svobodová, M.; Zídková, L.; Cepicka, I.; Obornik, M.; Lukes, J.; Votrpka, J. Sergeia podlipaevi gen. Nov., sp. voc. (Tryoanosomatida, Kinetoplastida), parasite of biting midges (Ceratopogonidae, Diptera). Int. J. Syst. Evol. Microbiol. 2007, 57, 423-432. [CrossRef] [PubMed]

3. Jaskowska, E.; Mayordomo, C.; Preston, G.; Kelly, S. Phytomonas: Tripanosomátidos adaptados a los ambientes vegetales. PLoS Pathog. 2015, 11, e1004484.

4. Seward, E.A.; Votypka, J.; Kment, P.; Lukes, J.; Kelly, S. Description of Phytomonas oxycareni n. sp. from the Salivary Glands of Oxycarenus lavaterae. Protist 2017, 168, 71-79. [CrossRef] [PubMed]

5. Hamilton, P.B.; Gibson, W.C.; Stevens, J.R. Patterns of co-evolution between trypanosomes and their hosts deduced from ribosomal RNA and protein-coding gene phylogenies. Mol. Phylogenetics Evol. 2007, 44, 15-25. [CrossRef] [PubMed]

6. Stevens, J.; Noyes, H.; Gibson, W. The evolution of Trypanosomes infecting humans and primates. Mem. Do Inst. Oswaldo Cruz 1998, 93, 669-676. [CrossRef]

7. Viola, L.B.; Attias, M.; Takata, C.S.A.; Campaner, M.; De Souza, W.; Camargo, E.P.; Texeira, M.M.G. Phylogenetic analyses based on small subunit rRNA and glycosomal glyceraldehyde-3-phosphate dehydrogenase genes and ultrastructural characterization of two snake Trypanosomes: Trypanosoma serpentis n. sp. from Pseudoboa nigra and Trypanosoma cascavelli from Crotalus durissus terrificus. J. Eukaryot. Microbiol. 2009, 56, 594-602.

8. Maslov, D.; Podlipaev, S.; Lukes, J. Phylogeny of the Kinetoplastida: Taxonomic Problems and Insights into the evolution of Parasitism. Mem. Do Inst. Oswaldo Cruz. 2001, 96, 397-402. [CrossRef]

9. Kaufer, A.; Ellis, J.; Stark, D.; Barratt, K. The evolution of trypanosomatid taxonomy. Parasites Vectors 2017, 10, 287. [CrossRef] 
10. Ortiz, P.A.; Herakles, A.G.; Lima, L.; da Silva, F.M.; Campaner, M.; Pereira, C.L.; Juttapalapong, S.; Neves, L.; Desquesnes, M.; Camargo, E.P.; et al. Diagnosis and genetic analysis of the worldwide distributed Rattus-borne Trypanosome (Herpetosoma) lewisi and its allied species in blood and fleas of rodents. Infect. Genet. Evol. 2018, 63, 380-390. [CrossRef]

11. Dario, M.A.; Moratelli, R.; Schwalbl, P.; Jansen, A.M.; Llewellyn, M.S. Small subunit ribosomal metabarcoding reveals extraordinary Trypanosomatid diversity in Brazilian bats. PLoS Negl. Trop. Dis. 2017, 11, e0005790. [CrossRef]

12. Naiff, R.D.; Barrett, T.V.; Freitas, R.A. Isolation of Trypanosoma freitasi (kinetoplastida: Trypanosomatidae) from Psychodopygus claustrei (Diptera: Psychodidae). Mem. Do Inst. Oswaldo Cruz 1989, 84, 273-275. [CrossRef]

13. Naiff, R.D.; Barrett, T.V. Trypanosoma (Megatrypanum) lainsoni n. sp. from Mesomys hispidus (Rodentia: Echimyidae) in Brazil: Trypomastigotes described from experimentally infected laboratory mice. Parasite 2013, 20, 51. [CrossRef] [PubMed]

14. Fermino, B.R.; Paiva, F.; Viola, L.B.; Rodrigues, C.M.; Garcia, H.A.; Campaner, M.; Takata, C.S.; Sheferaw, D.; Kisakye, J.J.; Kato, A.; et al. Shared species of crocodilian trypanosomes carried by tabanid flies in Africa and South America, including the description of a new species from caimans, Trypanosoma kaiowa $\mathrm{n}$. sp. Parasites Vectors 2019, 12, 225. [CrossRef] [PubMed]

15. Lemos, M.; Morais, D.H.; Carvalho, V.T.; D'agosto, M. First record of Trypanosoma chattoni in Brazil and occurrence of other Trypanosoma species in Brazilian frogs (Anura, Leptodactylidae). J. Parasitol. 2008, 94, 148-151. [CrossRef] [PubMed]

16. Eberhardt, A.T.; Monje, L.D.; Zurvera, D.A.; Beldomenico, P.M. Detection of Trypanosoma evansi infection in wild capybaras from Argentina using smear microscopy and real-time PCR assays. Vet. Parasitol. 2014, 202, 226-233. [CrossRef]

17. Monzón, C.M.; Mancebo, O.A.; Roux, J.P. Comparison between six parasitological methods for diagnosis of Trypanosoma evansi in the subtropical area of Argentina. Vet. Parasitol. 1990, 36, 141-146. [CrossRef]

18. Monzón, C.M.; Mancebo, O.A.; Gimenez, J.M.; Russo, A.M. Evolución de la Trypanosomiasis bovina por Trypanosoma vivax en Formosa (Argentina). Años 2007-2012 y su potencial dispersión en el país. Ibero-Latinoam. Parasitol. 2013, 72, 38-44.

19. Schijman, S.G. Molecular diagnosis of Trypanosoma cruzi. Acta Trop. 2018, 184, 59-66. [CrossRef]

20. Sant'Anna, C.; Pereira, M.G.; Lemgruber, L.; de Souza, W.; Cunha e Silva, N.L. New insights into the morphology of Trypanosoma cruzi reservosome. Microsc. Res. Tech. 2008, 71, 599-605. [CrossRef]

21. Ayala, S.C.; Mckay, J.G. Trypanosoma gerrhonoti n. sp., and extrinsic development of lizard trypanosomes in California sandflies. J. Protozool. 1971, 18, 430-433. [CrossRef]

22. Heoare, C.A. Morphological and taxonomic studies on mammalian trypanosomes X. Revision of the systematics. J. Protozool. 1964, 11, 200-207. [CrossRef] [PubMed]

23. Ayala, S.C. Two new Trypanosomes from California toads and Lizards. J. Protozool. 1970, 17, $370-373$. [CrossRef]

24. Fisher, A.C.; Schuster, G.; Cobb, W.J.; James, A.M.; Cooper, S.M.; de León, A.A.; Holman, P.J. Molecular characterization of Trypanosoma (Megatrypanum) spp. infecting cattle (Bos taurus), white-tailed deer (Odocoileus virginianus), and elk (Cervus elaphus canadensis) in the United States. Vet. Parasitol. 2013, 197, 29-42. [CrossRef] [PubMed]

25. Martins, J.R.; Leite, R.C.; Doyle, R.L. Tripanosomatides like Trypanosoma theileri in the cattle tick Boophilus microplus. Braz. J. Vet. Parasitol. 2008, 17, 113-114. [CrossRef] [PubMed]

26. Morzaria, S.P.; Latif, A.A.; Jongejan, F.; Walker, A.R. Transmission of a Trypanosoma sp. to cattle by the tick Hyalomma anatolicum anatolicum. Vet. Parasitol. 1986, 19, 13-21. [CrossRef]

27. Viola, L.B.; Campaner, M.; Takata, C.S.; Ferreira, R.C.; Rodrigues, A.C.; Freitas, R.A.; Duarte, M.R.; Grego, K.F.; Barrett, T.V.; Camargo, E.P.; et al. Phylogeny of snake trypanosomes inferred by SSU rDNA sequences, their possible transmission by phlebotomines, and taxonomic appraisal by molecular, cross-infection and morphological analysis. Parasitology 2008, 135, 595-605. [CrossRef]

28. Coura, J.R. The main sceneries of Chagas disease transmission. The vectors, blood and oral transmissions-A comprehensive review. Mem. Do Inst. Oswaldo Cruz 2015, 110, 277-282. [CrossRef]

29. Bisceglia, S.B.C.; Pereira, J.A.; Teta, P.; Quintana, R.D. Food habits of Geoffroy's cat (Leopardus geoffroyi) in the central Monte desert of Argentina. J. Arid Environ. 2008, 72, 1120-1126. [CrossRef] 
30. Kollien, A.H.; Schaub, G.A. The development of Trypanosoma cruzi in triatominae. Parasitol. Today 2000, 16, 381-387. [CrossRef]

31. Hayes, P.M.; Lawton, S.P.; Smit, N.J.; Gibson, W.C.; Davies, A.J. Morphological and molecular characterization of a marine fish trypanosome from South Africa, including its development in a leech vector. Parasites Vectors 2014, 7, 50. [CrossRef]

32. Lemos, M.; Fermino, B.; Simas-Rodrigues, C.; Hoffmann, L.; Silva, R.; Camargo, E.; Texeira, M.; Sauto-Padro, T. Phylogenetic and morphological characterization of trypanosomes from Brazilian armoured carfishes and leeches reveal high species diversity, mixed infections and a new fish trypanosome specie. Parasites Vectors 2015, 8, 573-590. [CrossRef] [PubMed]

33. Kumar, S.; Stecher, G.; Tamura, K. Mega 7: Molecular Evolutionary Genetics Analysis Version 7.0 for Bigger Datasets. Soc. Mol. Biol. Evol. 2016, 33, 1870-1874. [CrossRef] [PubMed]

34. Tomasini, N.; Lauthier, J.J.; Llewellyn, M.S.; Diosque, P. MLSTest: Novel software for multi-locus sequence data analysis in eukaryotic organisms. Infect. Genet. Evol. 2013, 20, 188-196. [CrossRef] [PubMed]

35. Huelsenbeck, J.P.; Ronquist, F.; Nielsen, R.; Bollback, J.P. Bayesian inference of phylogeny and its impact on evolutionary biology. Science 2001, 294, 2310-2314. [CrossRef]

36. Miller, M.A.; Pfeiffer, W.; Schwartz, T. Creating the CIPRES Science Gateway for inference of large phylogenetic trees. In Proceedings of the Gateway Computing Environments Workshop (GCE), New Orleans, LA, USA, 14 November 2010; pp. 1-8.

37. Kimura, M. A simple method for estimating evolutionary rate of base substitutions through comparative studies of nucleotide sequences. J. Mol. Evol. 1980, 16, 111-120. [CrossRef]

38. Tamura, K. Estimation of the number of nucleotide substitutions when there are strong transition-transversion and G + C-content biases. Mol. Biol. Evol. 1992, 9, 678-687.

39. Hasegawa, M.; Kishino, H.; Yano, T.A. Dating of the human ape splitting by a molecular clock of mitochondrial-DNA. J. Mol. Evol. 1985, 22, 160-174. [CrossRef]

(C) 2020 by the authors. Licensee MDPI, Basel, Switzerland. This article is an open access article distributed under the terms and conditions of the Creative Commons Attribution (CC BY) license (http://creativecommons.org/licenses/by/4.0/). 